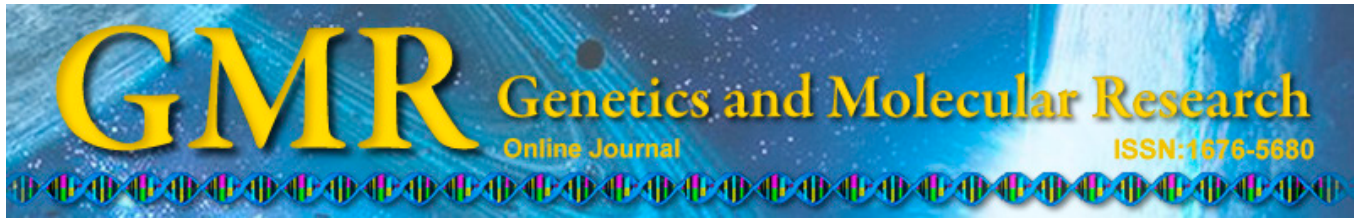

\title{
Mapping quantitative trait loci for sheath blight disease resistance in Yangdao 4 rice
}

\author{
Z.H. Wen*, Y.X. Zeng*, Z.J. Ji and C.D. Yang \\ State Key Laboratory of Rice Biology, China National Rice Research Institute, \\ Hangzhou, China \\ *These authors contributed equally to this study. \\ Corresponding author: C.D. Yang \\ E-mail: yangchangdeng@126.com \\ Genet. Mol. Res. 14 (1): 1636-1649 (2015) \\ Received February 10, 2014 \\ Accepted May 27, 2014 \\ Published March 6, 2015 \\ DOI http://dx.doi.org/10.4238/2015.March.6.10
}

\begin{abstract}
Rice sheath blight (ShB), which is caused by Rhizoctonia solani, has become the most serious rice disease in China. Yangdao 4, a cultivar with partial resistance to ShB, was crossed with Lemont, a susceptible cultivar, to develop mapping populations that were used to analyze quantitative trait loci (QTL) that confer resistance to ShB. QTL analysis were performed in 3 environments (E1-E3) using $2 F_{2}$ and 1 $\mathrm{F}_{2: 3}$ populations, respectively. Three traits were recorded to evaluate $\mathrm{ShB}$ resistance, including disease rating (DR), lesion height (LH), and percentage of lesion height (PLH). Based on field evaluation of ShB resistance and the 2 genetic maps constructed, we identified a total of 8 QTLs for DR (4 in E1, 4 in E2, and 3 in E3), 6 QTLs for LH (1 in E1, 3 in E2, and 2 in E3), and 7 QTLs for PLH (1 in E1, 4 in E2, and 2 in E3). Sixteen of the ShB-QTLs co-localized as 6 clusters on chromosomes $3,7,11$, and 12. Four of the 6 clusters contained ShB-QTLs that were detected in 2 environments, while the other 2 clusters with ShB-QTLs were detected in 1 environment. Three ShB-QTLs ( $q S B D-3-2, q S B L-$ $3-1$, and $q S B P L-3-1)$ were delimited to a $581-\mathrm{kb}$ region flanked by markers D333B and D334 on chromosome 3. The resistance alleles of
\end{abstract}


Yangdao 4 at the $q S B D-3-2$ locus decreased DR by 0.68 and 0.79 in E2 and $\mathrm{E} 3$, respectively.

Key words: Quantitative trait locus; Rice (Oryza sativa L.); Sheath blight (ShB); ShB-resistant cultivars

\section{INTRODUCTION}

Rice sheath blight ( $\mathrm{ShB}$ ) is one of the 3 major rice diseases and has become the most serious disease causing rice yield loss in China (Zou et al., 2000; Zeng et al., 2011). The soilborne pathogen Rhizoctonia solani is the causal agent of rice ShB. $R$. solani can infect a wide range of hosts and infects more than 200 plant species, including some of the most important crops worldwide (Lehtonen et al., 2008). A large number of rice accessions from different countries have been examined to identify resources for ShB resistance (Pan et al., 2001; Srinivasachary et al., 2011; Jia et al., 2012). Thus far, no rice germplasm has been identified that is immune to this fungus. However, some resistance varieties and lines have been shown to offer sufficient partial resistance against the pathogen under field conditions (Sato et al., 2004), showing potential for the breeding of ShB-resistant cultivars.

Rice $\mathrm{ShB}$ resistance is generally considered to be a typical quantitative trait controlled by quantitative trait loci (QTL), but a few studies proposed that $\mathrm{ShB}$ resistance in some rice varieties is controlled by major genes (Che et al., 2003; Xiang et al., 2007). ShB-QTL have been mapped on all 12 rice chromosomes using different mapping populations (Li et al., 1995; Pan et al., 1999; Zou et al., 2000; Han et al., 2002; Kunihiro et al., 2002; Sato et al., 2004; Pinson et al., 2005; Tan et al., 2005; Sharma et al., 2009; Channamallikarjuna et al., 2010; Fu et al., 2011; Xu et al., 2011; Nelson et al., 2012; Eizenga et al., 2013; Liu et al., 2009, 2013; Taguchi-Shiobara et al., 2013). Furthermore, specific molecular markers have been found to be associated with rice ShB resistance (Xie et al., 2008; Eizenga et al., 2006, 2009; Li et al., 2009; Jia et al., 2012). However, only a few ShB-QTL have been fine-mapped, including $q S B R-11-1$ and $q S B-11^{L E}$ (Channamallikarjuna et al., 2010; Zuo et al., 2013). The phenotypic effects of several ShB-QTL have also been evaluated (Wang et al., 2012b).

Two agronomic traits, plant height $(\mathrm{PH})$ and heading date, were reported to be correlated with ShB resistance (Zou et al., 2000; Kunihiro et al., 2002; Sato et al., 2004; Li et al., 1995, 2009; Channamallikarjuna et al., 2010; Fu et al., 2011; Nelson et al., 2012; Eizenga et al., 2013), with some ShB-QTL co-localizing with either the PH-QTLs or the heading dateQTL (Li et al., 1995; Kunihiro et al., 2002; Fu et al., 2011).

The mechanisms responsible for resistance to rice ShB remain largely unknown. Two mechanisms contributing to ShB resistance were proposed by Srinivasachary et al. (2011), including physiological resistance (innate resistance) and disease escape. According to this hypothesis, ShB-QTL co-localized with the PH-QTL or that the heading dateQTL were responsible for disease escape, while other ShB-QTL contributed to physiological resistance.

An indica cultivar, Yangdao 4, has been reported to be the most resistant cultivar among 68 cultivars inoculated with the $R$. solani isolate RH-9 (Pan et al., 2001). To identify QTL that control ShB resistance in Yangdao 4, $2 \mathrm{~F}_{2}$ and $1 \mathrm{~F}_{2: 3}$ populations derived by crossing Lemont with Yangdao 4 were used in this study. The mapping populations were grown in 3 environments to test the stability of the ShB-QTL. We developed an approach for quickly 
detecting and confirming ShB-QTL when permanent populations (recombinant inbred line or doubled haploid line populations) are unavailable.

\section{MATERIAL AND METHODS}

\section{Plant materials and mapping populations}

The mapping populations were derived by crossing Lemont with Yangdao 4. Lemont is an US japonica cultivar susceptible to $R$. solani. Yangdao 4 is a Chinese indica cultivar released from Jiangsu Province and has been reported to show remarkable resistance to ShB (Pan et al., 2001).

Three mapping populations were used in this study: 1) A Lemont/Yangdao $4 \mathrm{~F}_{2}$ population, consisting of 190 individuals, was sown on May 27, 2011, on a farm at the China National Rice Research Institute in Fuyang, Hangzhou (119 $\left.95^{\prime} \mathrm{E}, 30^{\circ} 07^{\prime} \mathrm{N}\right)$ (Environment 1, E1). This population was used to construct the molecular marker linkage map and identify ShB-QTL. 2) A total of $190 \mathrm{~F}_{2: 3}$ family lines derived from the above population were planted on November 25, 2012, in Lingshui, Hainan $\left(110^{\circ} 02^{\prime} \mathrm{E}, 18^{\circ} 48^{\prime} \mathrm{N}\right)$ (Environment 2, E2) for QTL analysis. 3) Another Lemont/Yangdao $4 \mathrm{~F}_{2}$ population consisting of 188 individuals was planted on May 22, 2012, at the farm of China National Rice Research Institute in Hangzhou $\left(119^{\circ} 95^{\prime} \mathrm{E}, 30^{\circ} 07^{\prime} \mathrm{N}\right)$ (Environment 3, E3). This population was used to confirm the QTL detected in E1 and E2 (Figure 1).

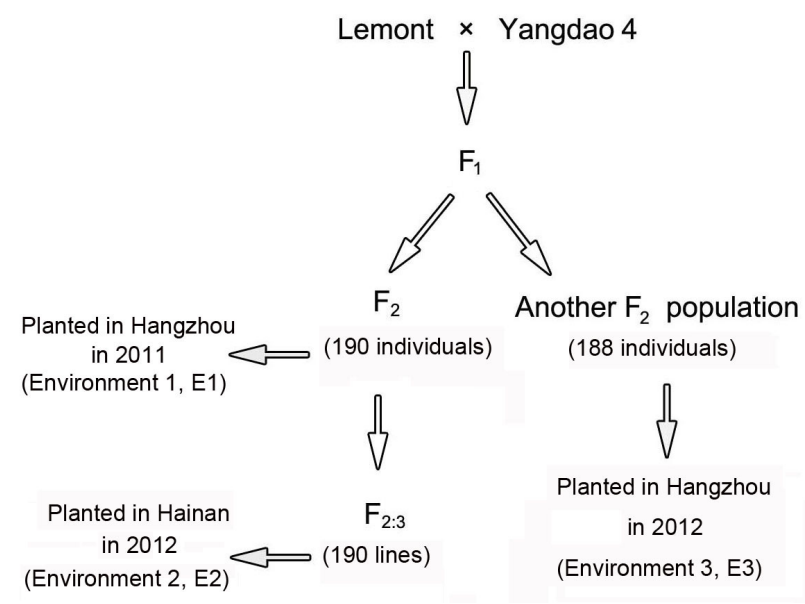

Figure 1. Mapping populations used in identifying ShB-QTLs in the three environments.

\section{Field evaluation of $\mathrm{ShB}$ resistance}

The $R$. solani isolate ZJ03 deposited in this lab was used for inoculation. Truncated bamboo-toothpicks (2-2.5 cm long) were used as inoculums for pathogen infection based on the method described by Zou et al. (2000), with some modification: the toothpicks were incubated with the ZJ03 strain on potato dextrose agar medium for 7 days at $28^{\circ} \mathrm{C}$, then inserted into the third leaf sheath, counting from the top during the late-tillering stage. The plant reac- 
tions to ShB were recorded 30 days after inoculation.

For the $\mathrm{F}_{2}$ population, 3 tillers of an individual plant were inoculated. The maximum disease score among the 3 tillers was considered to be the final disease reaction for the specific individual.

For the $\mathrm{F}_{2: 3}$ families, 18 individual plants within a family were grown. Two tillers of an individual plant were inoculated and the maximum disease score of the 2 tillers was considered to be the final disease reaction for the individual. The average disease score of the 18 individual plants was used as the disease reaction for the specific $\mathrm{F}_{2: 3}$ family line.

Three parameters were recorded to assess ShB resistance for each inoculated individual plant: 1) Disease rating (DR): the 0-9 rating scale system was used, where 0 indicated no disease and 9 indicated dead or collapsed plants (Rush et al., 1976). 2) Lesion height (LH): ShB lesions extending along the stem; LH was measured from the lowest site to the highest site. 3) Percentage of lesion height (PLH): $\mathrm{PLH}=\mathrm{LH} \div \mathrm{PH} \times 100 \%$. $\mathrm{PH}$ was measured from the soil surface to the tip of the tallest panicle at maturity (Sharma et al., 2009).

\section{Molecular marker assays}

A total of 507 simple sequence repeat (SSR) markers were screened for parental polymorphisms. Because the SSR marker polymorphisms were low between Lemont and Yangdao 4, we developed insertion-deletion (InDel) markers to augment the polymorphic markers (Zeng et al., 2013b). Using the $\mathrm{F}_{2}$ population planted in $\mathrm{E} 1$, a genetic linkage map with 180 markers was constructed, including 52 SSR markers and 128 InDel markers. SSR marker information can be downloaded from the Gramene database (http://www.gramene. org/). The forward and reverse sequences of the $128 \mathrm{InDel}$ markers were previously described by Zeng et al. (2013b). Based on the ShB-QTL identified in E1 and E2, the $\mathrm{F}_{2}$ population grown in E3 was assayed using 41 markers. The 41 markers covered the regions of the QTL detected in E1 and E2. DNA extraction and the polymerase chain reaction protocol were described previously (Zeng et al., 2013a).

\section{Construction of marker linkage map and statistical analyses}

The marker linkage map was constructed using the MAPMAKER/EXP 3.0 software (Lander et al., 1987). The Kosambi mapping function was used to transform recombination frequencies into genetic distances $(\mathrm{cM})$. The calculation of correlation coefficient and analysis of variance were run in the SAS software (version 8.1). Genetic and physical maps of the rice chromosomes were drawn using the MapChart software (version 2.1) (Voorrips, 2002).

\section{QTL mapping for ShB resistance}

Composite interval mapping was used to detect QTL for ShB resistance and PH using the Windows QTL Cartographer 2.5 software (Wang et al., 2012a). To compare the data with previously identified ShB-QTL, a limit of detection threshold of 3.0 was used to determine the presence of putative QTL. Two or more QTL with overlapping confidence intervals (limit of detection $>3.0$ ) were defined as a QTL cluster. 


\section{RESULTS}

\section{ShB resistance of parental cultivars}

Significant differences were found between Lemont and Yangdao 4 for DR, LH, and PLH when they were planted in E1 or E3 $(\mathrm{P}<0.01$ or $\mathrm{P}<0.05)$. However, no significant differences were detected between Lemont and Yangdao 4 for DR, LH, and PLH when they were planted in E2. Yangdao 4 had lower DR, LH, and PLH compared with Lemont in all 3 environments (Table 1).

Table 1. Disease rating (DR), lesion height (LH), percentage of lesion height (PLH), and plant height (PH) of the two parents grown in the three environments.

\begin{tabular}{|c|c|c|c|c|c|}
\hline \multirow[t]{2}{*}{ (Environment) Year/lo } & \multirow[b]{2}{*}{ Trait } & \multicolumn{2}{|c|}{ Range } & \multicolumn{2}{|c|}{ Mean \pm SD } \\
\hline & & Lemont & Yangdao 4 & Lemont & Yangdao 4 \\
\hline \multirow[t]{4}{*}{ (E1) 2011/Hangzhou } & $\mathrm{DR}$ & $7-7.5$ & $1.5-2.5$ & $7.2 \pm 0.3^{* *}$ & $2.0 \pm 0.5^{* *}$ \\
\hline & $\mathrm{LH}(\mathrm{cm})$ & $26.2-52.3$ & $2.4-22.5$ & $39.1 \pm 9.4^{* *}$ & $12.4 \pm 8.2 * *$ \\
\hline & PLH (\%) & $34.7-69.3$ & $2.0-18.4$ & $51.8 \pm 12.5^{* *}$ & $10.2 \pm 6.7 * *$ \\
\hline & $\mathrm{PH}(\mathrm{cm})$ & $72.3-79.8$ & $114.3-129.2$ & $75.5 \pm 3.9 * *$ & $122.3 \pm 7.5^{* *}$ \\
\hline \multirow[t]{4}{*}{ (E2) 2012/Hainan } & $\mathrm{DR}$ & 6-7 & 4-6 & $6.7 \pm 0.6$ & $5.2 \pm 1.0$ \\
\hline & $\mathrm{LH}(\mathrm{cm})$ & $22.2-39.1$ & $18.9-31.9$ & $32.6 \pm 6.7$ & $26.1 \pm 5.2$ \\
\hline & PLH (\%) & $25.6-45.1$ & $22.3-37.6$ & $37.6 \pm 7.8$ & $30.8 \pm 6.1$ \\
\hline & $\mathrm{PH}(\mathrm{cm})$ & $83.9-90.6$ & $84.1-85.5$ & $86.7 \pm 3.5$ & $84.8 \pm 0.7$ \\
\hline \multirow[t]{4}{*}{ (E3) 2012/Hangzhou } & DR & $3-7$ & $0.5-1.5$ & $5.5 \pm 2.18^{*}$ & $1 \pm 0.5^{*}$ \\
\hline & $\mathrm{LH}(\mathrm{cm})$ & $24.3-53.9$ & $4.5-28.3$ & $31.1 \pm 9.7 * *$ & $15.9 \pm 9.1^{* *}$ \\
\hline & PLH (\%) & $30.8-68.4$ & $3.7-23.2$ & $39.4 \pm 12.3 * *$ & $13.0 \pm 7.5^{* *}$ \\
\hline & $\mathrm{PH}(\mathrm{cm})$ & $77.4-79.5$ & $111.0-128.1$ & $78.8 \pm 1.2 * *$ & $122.0 \pm 9.6^{* *}$ \\
\hline
\end{tabular}

$* \mathrm{P}<0.05 ; * * \mathrm{P}<0.01$.

Analysis of variance was conducted to test the influence of the environment on $\mathrm{ShB}$ resistance of the 2 parents. The results showed that the DR, LH, and PLH of Yangdao 4 were significantly different when grown in Hangzhou (E1 or E3) than in Hainan (E2), but the DR and LH of Lemont were not significantly different among the 3 environments (Table 2). This suggests that compared to Lemont, the ShB resistance of Yangdao 4 was more easily influenced by the environment.

Table 2. Effect of environment on ShB resistance and plant height of Lemont and Yangdao 4 as demonstrated by ANOVA $(\mathrm{P}<0.05$ were listed).

\begin{tabular}{lllrr}
\hline Cultivar & Trait & Comparison & F value & P value \\
\hline Lemont & PLH & 2011Hangzhou (E1) vs 2012Hainan (E2) & 5.62 & 13.75 \\
& PH & 2011Hangzhou (E1) vs 2012Hainan (E2) & 13.72 & 0.039 \\
Yangdao 4 & PH & 2012Hangzhou (E3) vs 2012Hainan (E2) & 22.56 & 39.06 \\
& DR & 2011Hangzhou (E1) vs 2012Hainan (E2) & 12.02 & 0.021 \\
& DR & 2012Hangzhou (E3) vs 2012Hainan (E2) & 31.17 & 0.009 \\
& LH & 2011Hangzhou (E1) vs 2012Hainan (E2) & 22.54 & 0.003 \\
& LH & 2012Hangzhou (E3) vs 2012Hainan (E2) & 74.14 & 0.030 \\
& PLH & 2011Hangzhou (E1) vs 2012Hainan (E2) & 45.16 \\
\hline
\end{tabular}




\section{Distribution of ShB resistance in the 3 mapping populations}

The DR, LH, and PLH in the 3 mapping populations were continuously distributed over wide ranges. The distributions of DR, $\mathrm{LH}$, and PLH in the $\mathrm{F}_{2}$ population planted in $\mathrm{E} 1$ and the distribution of DR in the $\mathrm{F}_{2}$ population planted in E3 were not normally distributed (Figure 2).
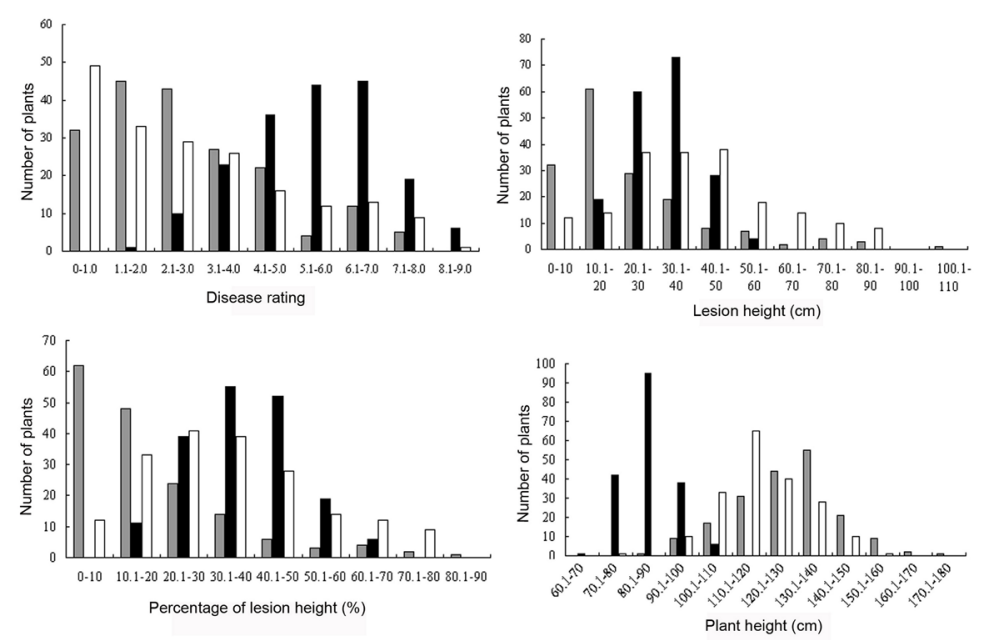

Figure 2. Distribution of the disease rating (DR), lesion height (LH), percentage of lesion height (PLH), and plant height $(\mathrm{PH})$ in the three mapping populations. Gray, black, and white columns indicate the three mapping populations growing in environment 1 (E1), environment 2 (E2) and environment 3 (E3), respectively.

\section{Construction of genetic linkage maps}

Two genetic linkage maps were constructed. 1) The first map consisting of 180 markers was constructed using $190 \mathrm{~F}_{2}$ individuals planted in E1. This map represents a total of $1996.2 \mathrm{cM}$ of the genetic distance at an average of $11.8 \mathrm{cM}$ between linked marker loci. The 180 markers were grouped into 13 linkage groups (Figure 3). 2) The second map with 41 markers was constructed using $188 \mathrm{~F}_{2}$ individuals grown in E3. This map represents a total of $389.8 \mathrm{cM}$ with an average of $13.3 \mathrm{cM}$ between adjacent markers. The 41 markers were grouped into 11 linkage groups (Figure 4).

\section{QTLs for ShB resistance}

A total of 8 QTL for DR were detected in the 3 mapping populations, located on chromosomes 1, 3, 7, 11, and 12 (Figure 3). The resistance alleles $q S B D-1, q S B D-11-1$, and $q S B D$ 11-2 from Lemont individually explained $1.56-15.19 \%$ of the total phenotypic variation, and the alleles $q S B D-3-1, q S B D-3-2, q S B D-7, q S B D-12-1$, and $q S B D-12-2$ from Yangdao 4 explained $1.12-14.66 \%$ of the total phenotypic variation. The DR-QTL $q S B D-3-1$ was identified on chromosome 3 in both E1 and E3. The DR-QTL $q S B D-3-2$ was mapped onto chromosome 3 in both E2 and E3. The DR-QTL $q S B D-11-1$, located on chromosome 11 and flanked by markers D1103 and RM26155, were detected in both E1 and E2. These DR-QTL detected in 2 environments were more stable than those detected in 1 environment. 

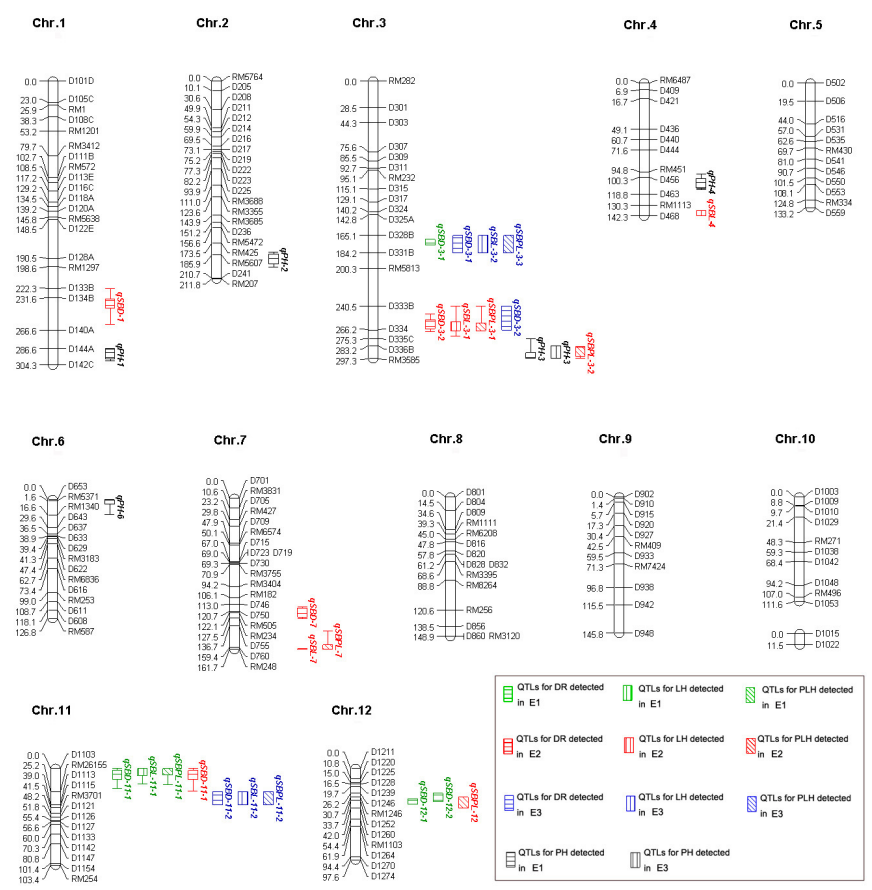

Figure 3. Chromosomal locations of the ShB-QTLs identified in the three environments. Numbers at the left of the chromosome bars indicate genetic position $(\mathrm{cM})$ of the corresponding markers. QTL for plant height $(\mathrm{PH}) \mathrm{was}$ not detected in E2.

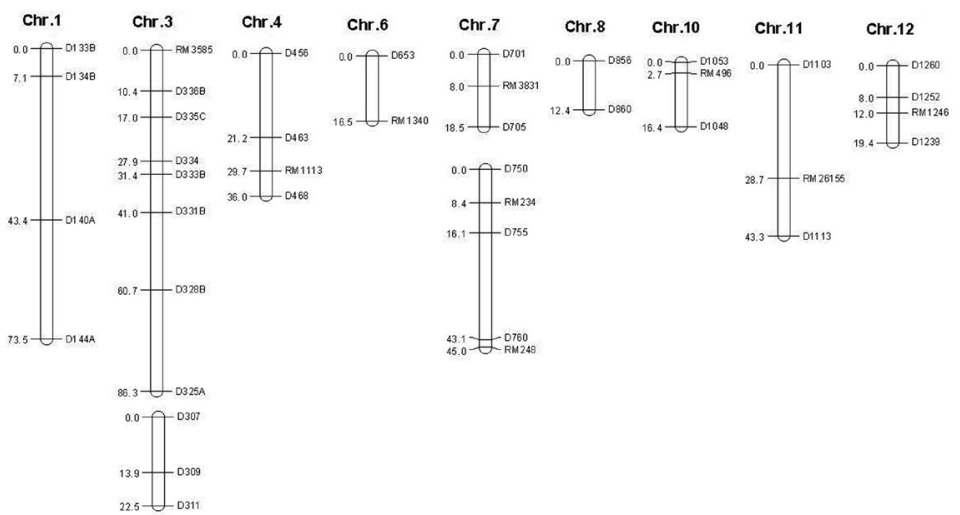

Figure 4. Genetic linkage map constructed using $188 \mathrm{~F}_{2}$ individuals grown in E3.

Six QTLs for LH ( $q S B L-3-1, q S B L-3-2, q S B L-4, q S B L-7, q S B L-11-1$, and $q S B L-11$ 2) were detected in 3 environments. The resistance alleles $q S B L-11-1$ and $q S B L-11-2$ from Lemont accounted for 2.28 and $12.58 \%$ of the total phenotypic variation, respectively. The alleles $q S B L-3-1, q S B L-3-2, q S B L-4$, and $q S B L-7$ from Yangdao 4 accounted for $4.15-31.53 \%$ of the phenotypic variation. Although all 6 LH-QTL were detected in only 1 environment, some were co-localized with the DR-QTL, including $q S B L-3-2$ and $q S B D-3-1, q S B L-3-1$ and $q S B D-3-2, q S B L-11-1$ and $q S B D-11-1$, and $q S B L-11-2$ and $q S B D-11-2$ (Figure 3 and Table 3). 
Table 3. QTLs for disease rating (DR), lesion height (LH), and percentage of lesion height (PLH) identified in the three environments using composite interval mapping.

\begin{tabular}{|c|c|c|c|c|c|c|c|c|c|c|}
\hline $\begin{array}{l}\text { (Environment) } \\
\text { Year/location }\end{array}$ & Trait & QTL & Chr. & LOD & $\begin{array}{l}\text { Marker interval } \\
\text { (Physical distance) }\end{array}$ & $\begin{array}{l}\text { Nearest } \\
\text { marker }\end{array}$ & $\begin{array}{c}\text { LOD peak } \\
\text { position }(\mathrm{cM})\end{array}$ & $\mathrm{R}^{2}(\%)$ & $\begin{array}{l}\text { Additive } \\
\text { effect }\end{array}$ & DPE \\
\hline \multirow[t]{6}{*}{$\begin{array}{l}\text { (E1) } \\
\text { 2011/Hangzhou }\end{array}$} & DR & $q S B D-3-1$ & 3 & 3.09 & $\begin{array}{l}\text { D328B-D331B } \\
(2842 \mathrm{~kb})\end{array}$ & D328B & 172.1 & 10.51 & 0.76 & $\mathrm{~L}$ \\
\hline & DR & $q S B D-11-1$ & 11 & 4.97 & $\begin{array}{l}\text { D1103-RM26155 } \\
\text { (2891 kb) }\end{array}$ & D1103 & 7.0 & 2.13 & -0.77 & Y \\
\hline & DR & $q S B D-12-1$ & 12 & 3.12 & $\begin{array}{l}\text { D1239-D1246 } \\
\text { (2696 kb) }\end{array}$ & D1246 & 23.7 & 10.49 & 0.56 & $\mathrm{~L}$ \\
\hline & DR & $q S B D-12-2$ & 12 & 3.74 & $\begin{array}{l}\text { RM1246-D1252 } \\
\text { (874 kb) }\end{array}$ & RM1246 & 31.7 & 11.95 & 0.56 & $\mathrm{~L}$ \\
\hline & LH & $q S B L-11-1$ & 11 & 4.48 & $\begin{array}{l}\text { D1103-RM26155 } \\
(2891 \mathrm{~kb})\end{array}$ & D1103 & 3.0 & 2.28 & -8.26 & Y \\
\hline & PLH & $q S B P L-11-1$ & 11 & 4.89 & $\begin{array}{l}\text { D1103-RM26155 } \\
(2891 \mathrm{~kb})\end{array}$ & D1103 & 2.0 & 2.82 & -0.07 & Y \\
\hline \multirow[t]{11}{*}{$\begin{array}{l}\text { (E2) } \\
\text { 2012/Hainan }\end{array}$} & DR & $q S B D-1$ & 1 & 4.23 & $\begin{array}{l}\text { D134B-D140A } \\
(5521 \mathrm{~kb})\end{array}$ & D134B & 238.6 & 5.53 & -0.66 & Y \\
\hline & DR & $q S B D-3-2$ & 3 & 3.44 & $\begin{array}{l}\text { D333B-D334 } \\
(581 \mathrm{~kb})\end{array}$ & D334 & 260.5 & 9.84 & 0.68 & $\mathrm{~L}$ \\
\hline & DR & $q S B D-7$ & 7 & 3.91 & $\begin{array}{l}\text { RM505-RM234 } \\
\text { (946 kb) }\end{array}$ & RM505 & 122.1 & 1.12 & 0.15 & $\mathrm{~L}$ \\
\hline & DR & $q S B D-11-1$ & 11 & 3.71 & $\begin{array}{l}\text { D1103-RM26155 } \\
\text { (2891 kb) }\end{array}$ & D1103 & 7.0 & 1.56 & -0.57 & Y \\
\hline & LH & $q S B L-3-1$ & 3 & 5.34 & $\begin{array}{l}\text { D333B-D334 } \\
(581 \mathrm{~kb})\end{array}$ & D334 & 262.5 & 7.93 & 4.58 & $\mathrm{~L}$ \\
\hline & LH & $q S B L-4$ & 4 & 3.35 & $\begin{array}{l}\text { RM1113-D468 } \\
\text { (1175 kb) }\end{array}$ & D468 & 142.3 & 4.15 & 3.73 & $\mathrm{~L}$ \\
\hline & LH & $q S B L-7$ & 7 & 3.12 & $\begin{array}{l}\text { D760-RM248 } \\
(77 \mathrm{~kb})\end{array}$ & RM248 & 161.7 & 4.82 & 3.91 & $\mathrm{~L}$ \\
\hline & PLH & $q S B P L-3-1$ & 3 & 5.70 & $\begin{array}{l}\text { D333B-D334 } \\
(581 \mathrm{~kb})\end{array}$ & D334 & 264.5 & 8.70 & 8.63 & $\mathrm{~L}$ \\
\hline & PLH & $q S B P L-3-2$ & 3 & 4.04 & $\begin{array}{l}\text { D336B-RM3585 } \\
\text { (919 kb) }\end{array}$ & D336B & 290.2 & 15.90 & -7.12 & $\mathrm{Y}$ \\
\hline & PLH & $q S B P L-7$ & 7 & 5.07 & $\begin{array}{l}\text { D760-RM248 } \\
(77 \mathrm{~kb})\end{array}$ & RM248 & 161.7 & 6.97 & 5.65 & $\mathrm{~L}$ \\
\hline & PLH & $q S B P L-12$ & 12 & 3.31 & $\begin{array}{l}\text { RM1246-D1260 } \\
\text { (3351 kb) }\end{array}$ & D1252 & 33.7 & 6.99 & 4.87 & $\mathrm{~L}$ \\
\hline \multirow[t]{7}{*}{$\begin{array}{l}\text { (E3) } \\
\text { 2012/Hangzhou }\end{array}$} & DR & $q S B D-3-1$ & 3 & 4.45 & $\begin{array}{l}\text { D328B-D331B } \\
(2842 \mathrm{~kb})\end{array}$ & D331B & NP & 14.66 & 1.06 & $\mathrm{~L}$ \\
\hline & DR & $q S B D-3-2$ & 3 & 3.85 & $\begin{array}{l}\text { D333B-D334 } \\
(581 \mathrm{~kb})\end{array}$ & D334 & NP & 11.25 & 0.79 & $\mathrm{~L}$ \\
\hline & DR & $q S B D-11-2$ & 11 & 6.19 & $\begin{array}{l}\text { RM26155-D1113 } \\
\text { (1831 kb) }\end{array}$ & RM26155 & NP & 15.19 & -1.25 & $\mathrm{Y}$ \\
\hline & LH & $q S B L-3-2$ & 3 & 7.57 & $\begin{array}{l}\text { D328B-D331B } \\
\text { (2842 kb) }\end{array}$ & D328B & NP & 31.53 & 12.56 & $\mathrm{~L}$ \\
\hline & LH & $q S B L-11-2$ & 11 & 4.57 & $\begin{array}{l}\text { RM26155-D1113 } \\
\text { (1831 kb) }\end{array}$ & D1113 & NP & 12.58 & -9.59 & Y \\
\hline & PLH & $q S B P L-3-3$ & 3 & 7.00 & $\begin{array}{l}\text { D328B-D331B } \\
\text { (2842 kb) }\end{array}$ & D328B & NP & 29.81 & 10.76 & $\mathrm{~L}$ \\
\hline & PLH & $q S B P L-11-2$ & 11 & 3.70 & $\begin{array}{l}\text { RM26155-D1113 } \\
(1831 \mathrm{~kb})\end{array}$ & RM26155 & NP & 12.27 & -6.79 & $\mathrm{Y}$ \\
\hline
\end{tabular}

Physical distances based on Nipponbare reference sequence. NP, not presented since these QTLs were detected using a different genetic linkage map. DPE, direction of phenotypic effect. L and Y denote Lemont and Yangdao 4 alleles increasing the phenotypic values, respectively.

A total of 7 QTLs for PLH ( $q S B P L-3-1, q S B P L-3-2, q S B P L-3-3, q S B P L-7, q S B P L-11-1$, $q S B P L-11-2$, and $q S B P L-12)$ were identified. The alleles $q S B P L-3-2, q S B P L-11-1$, and qSBPL-11-2 from Lemont explained 2.82-15.90\% of the phenotypic variation, while the alleles qSBPL-3-1, qSBPL-3-3, qSBPL-7, and $q S B P L-12$ from Yangdao 4 explained 6.97-29.81\% of the phenotypic variation. All 7 PLH-QTLs were detected in 1 environment, some of which 
co-localized with the DR-QTL or LH-QTL.

By comparing the locations of the ShB-QTL detected in 3 environments, we found 6 ShB-QTL clusters consisting of 16 co-localized ShB-QTL: 2 clusters on chromosome 3 (D328B-D331B and D333B-D334 intervals), 1 on chromosome 7 (D760-RM248 interval), 2 on chromosome 11 (D1103-RM26155 and RM26155-D1113 intervals) and 1 on chromosome 12 (RM1246-D1260 interval). Of the 6 clusters, 2 clusters (D760-RM248 and RM26155D1113 intervals) showed ShB-QTL in only 1 environment, while the other 4 clusters showed ShB-QTL in 2 environments.

The physical distance between the markers D333B and D334 was $581 \mathrm{~kb}$ according to the Nipponbare sequences. Three ShB-QTLs ( $q S B D-3-2, q S B L-3-1$, and $q S B P L-3-1)$ were identified in this $581-\mathrm{kb}$ region while $q S B D-3-2$ was detected in 2 environments.

The DR-QTL $q S B D-12-2$, detected in E1, was delimited to an 874-kb region defined by markers RM1246 and D1252 on chromosome 12 . The region of $q S B P L-12$ overlapped with that of $q S B D-12-2$.

\section{Correlation between ShB resistance and plant height}

As shown in Table 4 , the correlations were significant $(\mathrm{P}<0.01$ or $\mathrm{P}<0.0001)$ between PH and DR, with correlation coefficients of $-0.327,-0.410$, and -0.256 in the 3 environments, respectively. The correlations between $\mathrm{PH}$ and LH were weak, and a significant correlation was detected only in E1 (correlation coefficient $=-0.232$ ). Highly significant negative correlations $(\mathrm{P}<0.0001)$ were detected between $\mathrm{PH}$ and $\mathrm{PLH}$, with correlation coefficients of $-0.352,-0.403$, and -0.336 in the 3 populations, respectively.

As expected, highly significant $(\mathrm{P}<0.0001)$ positive correlations were detected among DR, LH, and PLH in the 3 environments (Table 4).

\begin{tabular}{|c|c|c|c|c|c|}
\hline Environment & Item & DR & LH & PLH & $\mathrm{PH}$ \\
\hline \multirow[t]{4}{*}{ E1 } & DR & 1 & & & \\
\hline & LH & $0.810^{* *}$ & 1 & & \\
\hline & PLH & $0.824^{* *}$ & $0.987 * *$ & 1 & \\
\hline & $\mathrm{PH}$ & $-0.327 * *$ & $-0.232 *$ & $-0.352 * *$ & 1 \\
\hline \multirow[t]{4}{*}{ E2 } & DR & 1 & & & \\
\hline & LH & $0.919^{* *}$ & 1 & & \\
\hline & PLH & $0.966^{* *}$ & $0.955^{* *}$ & 1 & \\
\hline & $\mathrm{PH}$ & $-0.410^{* *}$ & -0.129 & $-0.403^{* *}$ & 1 \\
\hline \multirow[t]{4}{*}{ E3 } & DR & 1 & & & \\
\hline & LH & $0.803 * *$ & 1 & & \\
\hline & PLH & $0.818^{* *}$ & $0.972^{* *}$ & 1 & \\
\hline & $\mathrm{PH}$ & $-0.256^{*}$ & -0.131 & $-0.336^{* *}$ & 1 \\
\hline
\end{tabular}

$* * \mathrm{P}<0.0001 ; * \mathrm{P}<0.01$

\section{QTL for plant height}

In order to explore the relationship between $\mathrm{ShB}$ resistance and $\mathrm{PH}$, we mapped the QTL for PH in the 3 environments. Five QTL were detected in E1. No QTL was identified in E2. Only 1 QTL, $q P H-3$, was detected in E3. The $q P H-3$ was detected in both E1 and E3 (Table 5). It was found that 1 PH-QTL, $q P H-3$, co-localized with the ShB-QTL, $q S B P L-3-2$, 
at the D336B-RM3585 interval on chromosome 3. The limit of detection peak for $q P H-3$ was similar to marker RM3585, but the peak of $q S B P L-3-2$ was closer to marker D336B. The positions of the other PH-QTLs were different from the ShB-QTL.

\begin{tabular}{|c|c|c|c|c|c|c|c|c|c|}
\hline Environment & QTL & Chr. & LOD & $\begin{array}{l}\text { Marker interval } \\
\text { (Physical distance) }\end{array}$ & Nearest marker & $\begin{array}{l}\text { LOD peak } \\
\text { position }(\mathrm{cM})\end{array}$ & $\begin{array}{c}\mathrm{R}^{2} \\
\text { effect }\end{array}$ & Additive & DPE \\
\hline \multirow[t]{5}{*}{ E1 } & $q P H-1$ & 1 & 3.50 & $\begin{array}{l}\text { D144A-D142C } \\
(1315 \mathrm{~kb})\end{array}$ & D144A & 292.6 & 11.22 & 5.94 & $\mathrm{~L}$ \\
\hline & $q P H-2$ & 2 & 3.67 & $\begin{array}{l}\text { RM5607-D241 } \\
(2149 \mathrm{~kb})\end{array}$ & RM5607 & 190.9 & 11.22 & -4.49 & Y \\
\hline & $q P H-3$ & 3 & 16.41 & $\begin{array}{l}\text { D336B-RM3585 } \\
(919 \mathrm{~kb})\end{array}$ & RM3585 & 296.2 & 8.89 & 0.26 & $\mathrm{~L}$ \\
\hline & $q P H-4$ & 4 & 4.12 & $\begin{array}{l}\text { D456-D463 } \\
(3475 \mathrm{~kb})\end{array}$ & D456 & 107.3 & 0.97 & 0.83 & $\mathrm{~L}$ \\
\hline & $q P H-6$ & 6 & 5.22 & $\begin{array}{l}\text { D653-RM5371 } \\
(154 \mathrm{~kb})\end{array}$ & D653 & 0 & 16.23 & -5.64 & $\mathrm{Y}$ \\
\hline E3 & $q P H-3$ & 3 & 3.76 & $\begin{array}{l}\text { D336B-RM3585 } \\
(919 \mathrm{~kb})\end{array}$ & RM3585 & NP & 2.18 & 0.29 & $\mathrm{~L}$ \\
\hline
\end{tabular}

Physical distances based on Nipponbare reference sequence. NP, not presented. DPE, direction of phenotypic effect. $\mathrm{L}$ and $\mathrm{Y}$ denote Lemont and Yangdao 4 alleles increasing the phenotypic values, respectively.

\section{DISCUSSION}

\section{A fast approach for detecting ShB-QTL}

The disadvantage of using the $\mathrm{F}_{2}$ population for QTL mapping studies is that the replication of accurate phenotypic values is unavailable. The recombinant inbred line or double-haploid populations may be used to overcome this problem, but it takes longer time to develop recombinant inbred line populations and gamete selection in developing doublehaploid populations by anther cultures can affect the final mapping results (Zou et al., 2000). In order to quickly and accurately identify ShB-QTL in Yangdao 4, the strategy used in this study combined the $\mathrm{F}_{2}$ and $\mathrm{F}_{2: 3}$ populations to detect QTL in multiple environments. 1) A genetic linkage map was constructed using the $\mathrm{F}_{2}$ population planted in E1. QTL analysis was conducted in $\mathrm{E} 1$ ( $\mathrm{F}_{2}$ population) and $\mathrm{E} 2$ ( $\mathrm{F}_{2: 3}$ population). 2) Based on the QTL analysis results identified in $\mathrm{E} 1$ and $\mathrm{E} 2$, another $\mathrm{F}_{2}$ population planted in $\mathrm{E} 3$ was used to confirm the QTL identified in E1 and E2. 3) To reduce disease escape because of the limitation of single plants in the $\mathrm{F}_{2}$ population, we inoculated 3 tillers in a single $\mathrm{F}_{2}$ individual to increase the accuracy of the phenotypic data. Figure 3 shows that some ShB-QTL were detected in 2 environments, demonstrating that these ShB-QTL were stable across different environments and the feasibility of our QTL-mapping approach. These stable ShB-QTL co-localized to form 4 clusters: the D328B-D331B and D333B-D334 intervals on chromosome 3, the D1103-RM26155 interval on chromosome 11, and the RM1246-D1260 interval on chromosome 12 (Figure 3). These stable ShB-QTL loci have the potential for use in breeding ShB-resistant cultivars.

To accelerate QTL mapping process, we constructed 2 marker linkage maps: the first map contained 180 markers, while the second had only 41 markers. We used a small number of markers in the second linkage map to quickly confirm the ShB-QTL. These 41 markers covered the genomic regions of the QTL detected in E1 and E2. Consequently, some of the ShB-QTL may not be identified in E3 because of limitations in marker numbers in the second linkage map. 


\section{Comparison of the ShB-QTL in present and previous studies}

To compare the ShB-QTL identified in the present study with those detected in previous studies (Pan et al., 1999; Zou et al., 2000; Kunihiro et al., 2002; Sato et al., 2004; Pinson et al., 2005; Xie et al., 2008; Li et al., 1995, 2009; Sharma et al., 2009; Channamallikarjuna et al., 2010; Fu et al., 2011; Xu et al., 2011; Jia et al., 2012; Nelson et al., 2012; Eizenga et al., 2006, 2009, 2013; Liu et al., 2009, 2013; Zuo et al., 2013), a physical map was drawn based on the alignment of published markers in relation to the Nipponbare sequences in GenBank (Figure 5).
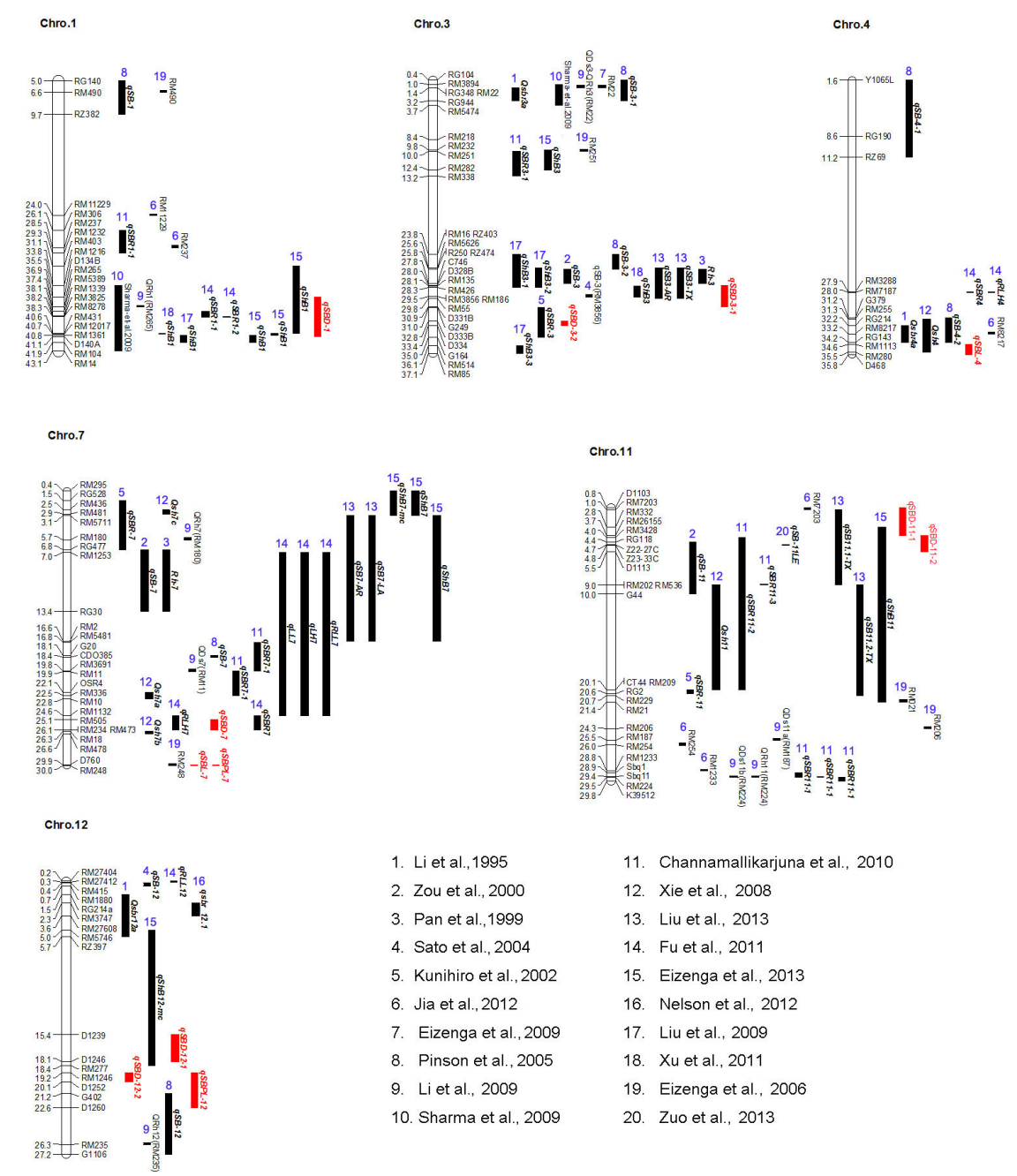

$$
\begin{aligned}
& \text { 11. Channamallikarjuna et al., } 2010 \\
& \text { 12. Xie et al., } 2008 \\
& \text { 13. Liu et al., } 2013 \\
& \text { 14. Fu et al., } 2011 \\
& \text { 15. Eizenga et al., } 2013 \\
& \text { 16. Nelson et al., } 2012 \\
& \text { 17. Liu et al., } 2009 \\
& \text { 18. Xu et al., } 2011 \\
& \text { 19. Eizenga et al., } 2006 \\
& \text { 20. Zuo et al., } 2013
\end{aligned}
$$

Figure 5. Physical map of the ShB-resistant QTLs (or markers associated with ShB resistance) identified in previous studies and in the present study. Black bars, QTLs or markers detected in previous studies; red bars, QTLs detected in this study. Numbers at the left of the chromosome bars indicate the physical distances $(\mathrm{Mb})$ of the corresponding markers. 
$q S B D-1$, which was detected in this study, was co-located (or located in similar positions) to $q S h B 1$ (Eizenga et al., 2013), qSBR1-1 (Fu et al., 2011), qSBR1-2 (Fu et al., 2011), qShB1 (Liu et al., 2009; Xu et al., 2011), and a QTL detected by Sharma et al. (2009) (Figure 5). qSBD-3-2, which was detected on chromosome 3, coincided with $q S B R-3$ (Kunihiro et al., 2002). According to Kunihiro et al. (2002), $q S B R-3$ co-located with the culm length QTL $q C L-3$. In this study, we did not observe the co-localization of PH-QTL with $q S B D-3-2$, but a PH QTL, $q P H-3$, was detected nearby. We were unable to determine whether $q S B D-3-2$ and $q S B R-3$ were the same locus based on the available data. The location of $q S B L-4$ overlapped with that of $Q s h 4$, which was detected by Xie et al. (2008). $q S B D-7$, which was detected on chromosome 7, co-localized with $q S B R 7$ and $q R L H 7$ as identified by Fu et al. (2011) (Figure 5). $q S B D-11-2$ was delimited to the RM26155-D1113 interval on chromosome 11, and a QTL $q S B-11^{L E}$ that was fine-mapped by Zuo et al. (2013) was also located in this region. Because the resistance alleles $q S B D-11-2$ and $q S B-11^{L E}$ were both from Lemont, they are likely the same locus.

\section{Novel ShB-QTLs detected in this study}

We identified 2 QTLs at the marker D760-RM248 interval on chromosome 7, where ShB-QTLs had not been mapped in previous studies (Figure 5). However, the marker RM248 was reported to be associated with ShB resistance by Eizenga et al. (2006).

$q S B D-12-2$, detected at the RM1246-D1252 interval on chromosome 12, is a novel ShB-QTL because ShB-QTL has not been previously observed in this region (Figure 5). The physical distance from RM1246 to D1252 is $875 \mathrm{~kb}$ based on the Nipponbare sequence. The QTL $q S B D-12-2$ detected in E1 overlapped with $q S B P L-12$ detected in E2. $q S B D-12-2$ was detected in only 1 environment, and its stability requires further investigation.

\section{Relationship between ShB resistance and plant height}

Several prior studies reported a negative correlation between $\mathrm{ShB}$ resistance and $\mathrm{PH}$ and co-localization of ShB-QTL and PH-QTL (Li et al., 1995; Zou et al., 2000; Kunihiro et al., 2002; Sato et al., 2004). In this study, a significant negative correlation was detected between PH and DR (or PLH) in all 3 environments and between PH and LH in E1. Co-localization of QTLs was also found: Of the 5 PH-QTLs detected, 1 of which, $q P H-3$, was co-localized with the ShB-QTL, $q S B P L-3-2$. The ShB-QTL and PH-QTL co-localized in the same genomic location because $\mathrm{ShB}$ resistance and $\mathrm{PH}$ are closely related: $\mathrm{ShB}$ disease severity generally decreases in individuals with taller $\mathrm{PH}$, assuming that the disease spreads at the same rate on short and tall plants, as our scoring system for ShB resistance was based on the infected proportion of the vegetative parts of the plant ( $\mathrm{Li}$ et al., 1995). Therefore, $\mathrm{PH}$ will inevitably affect $\mathrm{ShB}$ disease score using the current disease rating system, and some PH-QTL may be mistaken as 'ShB-QTL', indicating a pleiotropic effect of these PH-QTL. Caution should be used in evaluating 'ShB-QTL' that co-localize with PH-QTL. Only the ShB-QTL irrelevant to PH-QTL will be useful for developing ShB-resistant cultivars.

\section{ACKNOWLEDGMENTS}

Research supported by the National Natural Science Foundation of China (\#31101004, \#31221004), the "863" Program (\#2012AA101201), the National Technical Key Project of 
Transgenic New Variety Breeding (\#2011ZX08001-002, \#2013ZX08001-02), a fund in Zhejiang Province for public welfare (\#2014C32013), a special fund for Technical Innovation Team in Zhejiang Province (\#2010R50024), and a fund from the Chinese Academy of Agricultural Sciences to the Scientific and Technical Innovation Team.

\section{REFERENCES}

Channamallikarjuna V, Sonah H, Prasad M, Rao GJN, et al. (2010). Identification of major quantitative trait loci qSBR111 for sheath blight resistance in rice. Mol. Breed. 25: 155-166.

Che KP, Zhan QC, Xing QH, Wang ZP, et al. (2003). Tagging and mapping of rice sheath blight resistant gene. Theor. Appl. Genet. 106: 293-297.

Eizenga GC, Agrama HA, Lee FN, Yan W, et al. (2006). Identifying novel resistance genes in newly introduced blast resistant rice germplasm. Crop Sci. 46: 1870-1878.

Eizenga GC, Agrama HA, Lee FN and Jia Y (2009). Exploring genetic diversity and potential novel disease resistance genes in a collection of rice (Oryza spp.) wild relatives. Genet. Resour. Crop Evol. 56: 65-76.

Eizenga GC, Prasad B, Jackson AK and Jia MH (2013). Identification of rice sheath blight and blast quantitative trait loci in two different $O$. sativa/O. nivara advanced backcross populations. Mol. Breed. 31: 889-907.

Fu D, Chen L, Yu GH, Liu Y, et al. (2011). QTL mapping of sheath blight resistance in a deep-water rice cultivar. Euphytica 180: 209-218.

Han YP, Xing YZ, Chen ZX, Gu SL, et al. (2002). Mapping QTLs for horizontal resistance to sheath blight in an elite rice restorer line, Minghui 63. Acta Genet. Sin. 29: 622-626.

Jia LM, Yan WG, Zhu CS, Agrama HA, et al. (2012). Allelic analysis of sheath blight resistance with association mapping in rice. PLOS ONE 7: e32703.

Kunihiro Y, Qian Q, Sato H, Teng S, et al. (2002). QTL analysis of sheath blight resistance in rice (Oryza sativa L.). Acta Genet. Sin. 29: 50-55 (In Chinese with English abstract).

Lander ES, Green P, Abrahamson J, Barlow A, et al. (1987). MAPMAKER: an interactive computer package for constructing primary genetic linkage map of experimental and natural populations. Genomics 1: 174-181.

Lehtonen MJ, Somervuo P and Valkonen JPT (2008). Infection with Rhizoctonia solani induces defense genes and systemic resistance in potato sprouts grown without light. Phytopathology 98: 1190-1198.

Li F, Cheng LR, Xu MR, Zhou Z, et al. (2009). QTL mining for sheath blight resistance using the backcross selected introgression lines for grain quality in rice. Acta Agron. Sin. 35: 1729-1737.

Li ZK, Pinson SRM, Marchetti MA, Stansel JW, et al. (1995). Characterization of quantitative trait loci (QTLs) in cultivated rice contributing to field resistance to sheath blight (Rhizoctonia solani). Theor. Appl. Genet. 91: 382-388.

Liu G, Jia Y, Correa-Victoria FJ, Prado GA, et al. (2009). Mapping quantitative trait loci responsible for resistance to sheath blight in rice. Phytopathology 99: 1078-1084.

Liu G, Jia Y, McClung A, Oard JH, et al. (2013). Confirming QTLs and finding additional loci responsible for resistance to rice sheath blight disease. Plant Dis. 97: 113-117.

Nelson JC, Oard JH, Groth D, Utomo HS, et al. (2012). Sheath-blight resistance QTLS in japonica rice germplasm. Euphytica 184: 23-34.

Pan XB, Zou JH, Chen ZX, Lu JF, et al. (1999). Tagging major quantitative trait loci for sheath blight resistance in a rice variety, Jasmine 85. Chin. Sci. Bull. 44: 1783-1789.

Pan XB, Chen ZX, Zhang YF, Zhu J, et al. (2001). Preliminary evaluation for breeding advancement of resistance to rice sheath blight. Chin. J. Rice Sci. 15: 218-220.

Pinson SRM, Capdevielle FM and Oard JH (2005). Confirming QTLs and finding additional loci conditioning sheath blight resistance in rice using recombinant inbred lines. Crop Sci. 45: 503-510.

Rush MC, Hoff BJ and Mcllrath WO (1976). A uniform disease rating system for rice disease in the United States. Proceedings of the 16th Rice Tech, Working Group, Lake Charles, 64.

Sato H, Ideta O, Ando I, Kunihiro Y, et al. (2004). Mapping QTLs for sheath blight resistance in the rice line WSS2. Breed. Sci. 54: 265-271.

Sharma A, McClung AM, Pinson SRM, Kepiro JL, et al. (2009). Genetic mapping of sheath blight resistance QTLs within tropical japonica rice cultivars. Crop Sci. 49: 256-264.

Srinivasachary, Willocquet L and Savary S (2011). Resistance to rice sheath blight (Rhizoctonia solani Kuhn) [(Teleomorph: Thanatephorus cucumeris (A.B. Frank) Donk.] disease: current status and perspectives. Euphytica 178: 1-22.

Taguchi-Shiobara F, Ozaki H, Sato H, Maeda H, et al. (2013). Mapping and validation of QTLs for rice sheath blight 
resistance. Breed. Sci. 63: 301-308.

Tan CX, Ji XM, Yang Y, Pan XY, et al. (2005). Identification and marker-assisted selection of two major quantitative genes controlling rice sheath blight resistance in backcross generations. Acta Genet. Sin. 32: 399-405.

Voorrips RE (2002). Map Chart: software for the graphical presentation of linkage maps and QTLs. J. Hered. 93: 77-78.

Wang S, Basten CJ and Zeng ZB (2012a). Windows QTL Cartographer 2.5. Department of Statistics, North Carolina State University, Raleigh [http://statgen.ncsu.edu/qtlcart/WQTLCart.htm]. Accessed February 6, 2014

Wang Y, Pinson SRM, Fjellstrom RG and Tabien RE (2012b). Phenotypic gain from introgression of two QTL, qSB9-2 and qSB12-1, for rice sheath blight resistance. Mol. Breed. 30: 293-303.

Xiang XC, Li JH, Zhang KZ, Zhao P, et al. (2007). Genetic analysis of a rice mutant with resistance to sheath blight and its preliminary gene mapping. J. Southwest Univ. Sci. Technol. 22: 76-81.

Xie XW, Xu MR, Zang JP, Sun Y, et al. (2008). Genetic background and environmental effects on expression of QTL for sheath blight resistance in reciprocal introgression lines of rice. Acta Agron. Sin. 34: 1885-1893.

Xu Q, Yuan XP, Yu HY, Wang YP, et al. (2011). Mapping quantitative trait loci for sheath blight resistance in rice using double haploid population. Plant Breed. 130: 404-406.

Zeng YX, Ji ZJ, Ma LY, Li XM, et al. (2011). Advances in mapping loci conferring resistance to rice sheath blight and mining Rhizoctonia solani resistant resources. Rice Sci. 18: 56-66.

Zeng YX, Ma LY, Ji ZJ, Wen ZH, et al. (2013a). Fine mapping and candidate gene analysis of LM3, a novel lesion mimic gene in rice. Biologia 68: 82-90.

Zeng YX, Wen ZH, Ma LY, Ji ZJ, et al. (2013b). Development of 1047 insertion-deletion markers for rice genetic studies and breeding. Genet. Mol. Res. 12: 5226-5235.

Zou JH, Pan XB, Chen ZX, Xu JY, et al. (2000). Mapping quantitative trait loci controlling sheath blight resistance in two rice cultivars (Oryza sativa L.). Theor. Appl. Genet. 101: 569-573.

Zuo SM, Yin YJ, Pan CH, Chen ZX, et al. (2013). Fine mapping of $q S B-11^{L E}$, the QTL that confers partial resistance to rice sheath blight. Theor. Appl. Genet. 126: 1257-1272. 